\title{
As novas formas de organização familiar: um olhar histórico e psicanalítico
}

A família em desordem.

ROUDINESCO, Elizabeth. Tradução de Renato Aguiar.

Rio de Janeiro: Jorge Zahar Editor, 2003. $199 \mathrm{p}$.

Neste livro a psicanalista Elisabeth Roudinesco percorre o caminho da história da construção da família, atravessando os percursos psíquicos, políticos e econômicos que forneceram elementos para a construção dessa instituição, desde a antigüidade até a "pós-modernidade". Demarca os períodos e acontecimentos em oito capítulos intitulados "Deus pai", "A irrupção do feminino", "Quem matou o pai", "O filho culpado", "O patriarca mutilado", "As mulheres têm um sexo", "O poder das mães" e "A família do futuro".

Ao analisar a família ocidental, Roudinesco destaca três importantes períodos caracterizados por diferentes formas de organização familiar. No primeiro período forma-se a família tradicional pautada na preocupação com a transmissão de um patrimônio. Em um segundo momento a família passa a ser construída como fruto do amor romântico. E posteriormente a família moderna, contemporânea ou pós-moderna, fundamenta-se no amor e no prazer, com uma característica de atemporalidade, ou seja, a união dura enquanto durar o amor e o prazer. Para falar dessas três fases percorre, à luz da psicanálise, o caminho da história da formação das comunidades, das nações, do Estado, das religiōes.

Roudinesco apresenta o pai da família tradicional como a encarnação familiar de Deus. Sua autoridade jamais era contestada, e sua figura era sagrada: a imagem do Deus do Velho Testamento, do herói e do guerreiro. Com as transformações econômicas e políticas a autoridade paterna, imposta pela força, vai progressivamente perdendo espaço, e surge a reivindicação pela paternidade inspirada no Deus do Novo Testamento, um pai amoroso e amado, tolerante e respeitado. A família formada pela figura desse pai que respeita um "contrato social" é caracterizada pela compaixão.

Nessa nova família onde impera a compaixão, o pai aos poucos vai sendo destituído de autoridade e começa então a ressurgir a figura do feminino. O pai não é mais visto como o único responsável pela transmissão "psíquica e carnal" e a mãe assume responsabilidades nessa tarefa. Começa o temor da feminilização da sociedade.

O pai do início do século XIX, fragilizado por perder o lugar de um deus soberano, e conseqüentemente por perder a influência sobre - Estado, consegue se fortalecer através da economia. Tendo como modelo a figura cristã de José, carpinteiro e um patriarca amável, o novo pai constrói a partir de então a família econômica que caracterizou a "idade de ouro do paternalismo europeu". Como "pater famílias da coletividade industrial" assumiu a defesa da família contra a ferocidade do capitalismo nascente. Com a mesma coragem faz a defesa do operário, protegendo-o e fornecendo-lhe serviços de assistência básica. Assume então a função de "padre-padrone".

Seguindo a análise da autora, forma-se então a família econômico-burguesa, que se fundamenta na autoridade do marido, na subordinação das mulheres e na dependência dos filhos. Contudo, não é mais uma autoridade despótica; sua força é regulamentada pela lei do Estado (Declaração dos Direitos do Homem e do Cidadão, França, 1789). O Estado passa assim a acompanhar e intervir na vida familiar, em virtude da importância econômica que as famílias passam a desempenhar, tornando-se uma das estruturas de base da sociedade, "pois sem ela o Estado só poderia lidar com massas despóticas ou tribais" (p. 40). 
Roudinesco afirma que essas novas convenções exigem que o pai seja justo, submisso à lei e respeite os novos direitos adquiridos. Da mulher exige-se que seja "acima de tudo mãe, a fim de que o corpo social esteja em condições de resistir à tirania de um gozo feminino capaz, pensa-se, de eliminar a diferença dos sexos" ( $p$. 38). O casamento ganha outra face, perdendo a natureza divina e se consolidando como um acordo consensual entre um homem e uma mulher com duração relativa à durabilidade do amor. É o precedente para a instituição do divórcio na França em 1792.

Os recém-adquiridos direitos e deveres impõem ao pai o dever de respeitar o direito dos filhos. Se o comportamento do pai não estivesse de acordo com esses pressupostos, ele poderia perder o direito de ser pai. Surgia então o temor de que a sociedade fosse dominada pelas mulheres.

No campo teórico os debates sobre matriarcado x patriarcado entram em ebulição. Autores como Morgan e Engels assumem o eixo central das discussões sobre família Posteriormente, Freud insere-se nessa discussão, entendendo que a humanidade teve um salto qualitativo ao passar do matriarcado - mundo do sensível - ao patriarcado - mundo da razão. Entretanto, Freud, ao contrário de muitos de seus contemporâneos, não demonstrava temor a um possível domínio do feminino, muito menos de que este pudesse significar o declínio da razão.

Roudinesco acredita que a família do século XIX certamente foi abalada $e$ reestruturada a partir da invenção freudiana do complexo de Édipo.

A família edipiana é fundada no assassinato do pai pelo filho que deseja a mãe, e que começa a questionar a autoridade patriarcal. Da mesma forma, as filhas iniciam os seus questionamentos na tentativa de romper com a autoridade materna e alcançar a emancipação sexual. Essas descobertas ocorreram em um clima de terror apocalíptico diante de uma possível supressão das diferenças entre os sexos.

Para a autora, a fim de assegurar a cada um o seu lugar, ou seja, afirmar as diferenças entre sexos, pais, filhos e gerações, Freud reúne os fragmentos que restaram da sociedade patriarcal e coloca o pai com toda a glória e divindade de outrora, reinando atemporalmente no inconsciente, através da invenção do complexo de Édipo. Estabelece, portanto, de forma simbólica as convenções necessárias para a manutenção da família, que tem como eixo central a idéia da culpa.
O filho culpado por desejar a mãe, e assassinar o pai, torna-se um neurótico atordoado por seus "escrúpulos e remorsos". Para representar esse momento do drama, Freud escolhe o personagem de Shakespeare Hamlet, que seria então o Édipo adulto. Édipo é atormentado por um inconsciente desejante. Já Hamlet, carregando as conseqüências da tragédia edipiana, é um adulto dominado por sua consciência de culpa.

Através do sofrimento de Hamlet, Freud fala simbolicamente da condição de sofrimento do homem do século XIX, ao descobrir a existência do inconsciente e perceber que não detinha o controle de si, dos seus desejos e emoções. Não bastasse isso, descobriu também com Copérnico que não detinha o controle do universo, e com Darwin que não tinha uma origem tão divina e gloriosa como imaginava. Diante disto, e "Condenado a jamais ser rei, o herói do novo século galileiano busca sua identidade. Pode ele advir como um sujeito sem se desfazer de sua soberania de direito divino? Eis a questão" (p. 69).

Roudinesco assegura que de Édipo a Hamlet Freud buscou pensar a família procurando seu lugar simbólico nesse novo momento, tendo como realidade concreta a decadência da família burguesa vienense. Uma família que não era mais formada por um pai autoritário, ou mesmo por um pai que, desprovido do poder divino, garante o poder econômico e o bem-estar geral, mas ao contrário uma família dirigida por um filho que recebeu como herança a "figura destruída de um patriarca mutilado".

A autora aponta a família edipiana como o "paradigma do advento da família contemporânea", pois, ao colocar o complexo de Édipo como uma estrutura psíquica universal, universalizava-se também um modelo de relação conjugal entre homens e mulheres que se fundamentava no desejo e não mais na coerção das conveniências familiares. Assim, para a psicanálise, o amor e o desejo, o sexo e a paixão estavam fundamentalmente presentes nesse novo momento do matrimônio.

A nova organização familiar partindo do modelo edipiano sustentava-se em três pilares: "a revolução da afetividade, que exige cada vez mais que o casamento burguês seja associado ao sentimento amoroso e ao desabrochar da sexualidade feminina e masculina; o lugar preponderante concedido ao filho, que tem como efeito 'maternalizar' a célula familiar; a prática sistemática de uma contracepção espontânea, que dissocia o desejo sexual da 
procriação, dando assim origem a uma organização mais individual da família" (p. 96).

Com a maternalização da família, o poder do pai passou a ser cada vez mais abstrato, e contava unicamente com seu patrimônio para afirmar seu lugar simbólico. Já o filho assume uma posição mais central na família e deixa de ser visto como um objeto, para se colocar como um sujeito que significa uma continuidade ou um prolongamento dos pais, passando então a ser desejado. O lugar da mulher em progressiva emancipação a partir do final do século XVIII graças à organização do feminismo em movimento político - é ampliado sobretudo no campo da sexualidade. Na medida em que tem o prazer dissociado da finalidade de procriação, deixa de ser apenas esposa e mãe e vai se individualizando.

Ao perder o lugar de divindade, os homens perdiam também o controle sobre o corpo das mulheres, abrindo espaço para o desabrochar da sexualidade feminina, que surge fundada ao mesmo tempo sobre sexo e o gênero.

Com o avanço tecnológico da biomedicina, as mulheres conquistaram o controle não apenas do corpo mas da procriação, podendo, além de controlar a concepção, prescindir da participação direta do homem para a fecundação. Analisando esses fatos, Roudinesco afirma que "um fosso irreversível parece ter se cavado, pelo menos no Ocidente, entre $\circ$ desejo de feminilidade e $\circ$ desejo de maternidade, entre o desejo de gozar e o dever de procriar" (p. 146).

A possibilidade de formar uma família sem a necessidade do coito sexual, ou simplesmente de não desejar a maternidade, acompanhada por um crescente envolvimento dos homens na criação dos filhos, acena para uma necessidade de se repensar a instituição do casamento.

Todas essas transformações no modelo familiar tornaram essa instituição acessível também aos homossexuais, que sempre foram dela excluídos. A partir de 1965 gays e lésbicas passaram a reivindicar 0 direito a paternidade/ maternidade e "inventaram uma cultura da família que não passava, sob muitos aspectos, da perpetuação do modelo que haviam contestado e que já se encontrava ele próprio em plena mutação" (p. 181). De qualquer forma, transgrediram uma ordem moral que já durava mais de 2 mil anos.

Chegando nesse ponto do percurso histórico, Roudinesco afirma que, ao contrário do que se pensou, a família não se dissolveu, mas se reorganizou de forma horizontal e em redes, garantindo a reprodução das gerações. $O$ casamento perdeu o ornamento da sacralidade, e em constante declínio é hoje caracterizado pela união afetiva de cônjuges - com filhos ou não - que, buscando o refúgio das desordens do mundo exterior, unem-se não mais por uma vida, mas por um período aleatório que, como em mais de um terço dos casos, termina em divórcio, na maioria das vezes solicitado pelas mulheres, que ainda são as que inicialmente mais sofrem com os encargos dessa ruptura. Os filhos são freqüentemente concebidos fora dos laços matrimoniais, e esse quadro, que já aterrorizou muito, mostra-se hoje com naturalidade e comprova que a civilização não foi engolida por essas "desordens".

Roudinesco finaliza sua análise assegurando que, apesar das constantes transformações ocorridas na família ao longo dos séculos, ela continua a ser reivindicada por homens, mulheres e crianças, independentemente de idade, orientação sexual e classe social. Para a autora, a família "aparece em condições de se tornar um lugar de resistência à tribalização orgânica da sociedade globalizada" (p. 199), mas ressalta que para tanto a família do futuro precisa ser continuamente reinventada.

Adriana Rodrigues Universidade Federal de Santa Catarina 